\title{
Critical Discourse Analysis dalam Catatan Minggu: Teks dan Praksis dalam Narasi Urban
}

\author{
Gabriela Laras Dewi Swastika, Jennifer Esther \\ Fakultas Ilmu Komunikasi dan Bisnis Media, Universitas Ciputra Surabaya \\ gabriela.swastika@ciputra.ac.id
}

\begin{abstract}
Sunday is attached to several activities carried out in daily practice. Referring to religious rituals, Sunday is identical to the religious procession of Christianism; while based on the government calendar, most of Indonesian citizens enjoy a day off from work at the end of the week. This study examines content from the Sunday edition of the Kompas daily paper which is presented differently from content on other days of the week. Furthermore, this study specifically discusses three articles from the column of Catatan Minggu, featured on the Sunday edition of Kompas, entitled Yogya-Magelang which appeared on June 14 ${ }^{\text {th }} 2015$, Padang-Bukittinggi which appeared on June $28^{\text {th }} 2015$, and under the title Pada Setiap Sudut Kota New York which appeared on November 5th, 2017. The method used in this study is the critical discourse analysis from Teun A.Van Dijk who laid the foundation of discourse on sociocognitive order. This method is used to explore the formulation of the research problem; how is the interplay between text and praxis of urban narratives presented on the column of Catatan Minggu. The results of this research indicate that there is an accumulation of cultural, social, economic, and symbolic capital being articulated in the production of Catatan Minggu. The column of Catatan Minggu also shows the interplay between text and praxis, in which readers interpret the concepts of heim (private space) and heimat (public space) in the urban narrative it carries.
\end{abstract}

Keywords: critical discourse analysis (CDA); urban narrative; column; Catatan Minggu; Harian Umum Kompas

\begin{abstract}
Abstrak
Hari Minggu melekat pada beberapa aktivitas dalam praktik keseharian. Bila merujuk pada ritual keagamaan, hari Minggu identik dengan prosesi religi umat Kristen, sementara bila mengacu pada kalender pemerintah, sebagian besar masyarakat Indonesia sedang menikmati hari libur dari pekerjaan mereka di penghujung minggu. Penelitian ini membahas konten surat kabar Kompas di hari Minggu yang disajikan berbeda dengan konten di hari lainnya dalam seminggu. Penelitian menelaah tiga tulisan dalam kolom Catatan Minggu pada Kompas Minggu, yaitu tulisan berjudul Yogya-Magelang, PadangBukittinggi, dan Pada Setiap Sudut Kota New York. Metode yang digunakan dalam penelitian ini analisis wacana kritis dari Teun A. Van Dijk. CDA Van Dijk yang menaruh landasan diskursus (discourse) pada tatanan sosiokognitif. Metode ini digunakan untuk mengupas rumusan masalah penelitian: bagaimana interplay antara teks dan praksis dalam narasi urban yang terkandung dalam kolom Catatan Minggu. Hasil penelitian menunjukkan adanya akumulasi kapital budaya, sosial, ekonomi, dan simbolik dalam agenda produksi kolom Catatan Minggu. Kolom Catatan Minggu juga menunjukkan interplay antara teks dengan praksis, ketika para pembaca memaknai konsep heim (ruang privat) dan heimat (ruang publik) dalam narasi urban yang diusungnya.
\end{abstract}

Kata kunci: critical discourse analysis (CDA); narasi urban; kolom; Catatan Minggu; Harian Umum Kompas

Korespondensi: Gabriela Laras Dewi Swastika, S.I.Kom., M.A.; Fakultas Ilmu Komunikasi dan Bisnis Media, Universitas Ciputra Surabaya, CBD Boulervard, Citraland, Surabaya 60219; 08156864905, gabriela.swastika@ciputra.ac.id

Menyerahkan: Mei 2020, Diterima: Juli 2020, Terbit: Juli 2020

ISSN: 2549-0559 (cetak), ISSN: 2549-1946 (online), Website: http://jurnal.unpad.ac.id/kajian-jurnalisme 
DOI: $10.24198 / \mathrm{jkj} . v 4 \mathrm{i} 1.27276$

\section{PENDAHULUAN}

Apa yang terpikirkan saat melintas hari Minggu di kepala, apa yang ingin dilakukan ketika akhir pekan datang? Hari Minggu adalah hari di mana banyak orang melakukan hal-hal yang erat dengan praktik waktu luang. Bila dihubungkan dengan ritual religius, hari Minggu juga identik dengan ibadat orang-orang Kristen. Bila melihat kalender pemerintah, hampir sebagian besar masyarakat Indonesia menikmati waktu luang mereka di akhir pekan, tidak ada aktivitas sekolah, kampus, kantor-kantor pemerintah tutup, hanya sebagian fasilitas publik yang krusial tetap buka seperti rumah sakit.

Sejarah hari Minggu bisa ditelusuri hingga tahun 1630-an, di mana saat itu puritanisme berkembang, salah satunya di kawasan New England hingga abad ke-19. Saat itu hari Minggu hanya boleh dimanfaatkan untuk peribadatan di gereja-gereja dan kegiatan religius lainnya. Setelahnya, memasuki abad ke-20 banyak kegiatan yang dihubungkan dengan hari Minggu mulai mengalami perubahan. Alasannya adalah modernisasi yang kian meluas dan memasuki banyak aspek kehidupan, termasuk memasuki ranah privat, yang berkaitan dengan bagaimana masyarakat memanfaatkan keseharian mereka. Peribadatan dan kegiataan keagamaan Kristen tetap berjalan di hari Minggu, namun dikombinasikan dengan kegiatan akhir pekan lainnya, seperti olah raga, makan-makan, melakukan pelancongan, termasuk membaca surat kabar hari Minggu (cbsnews.com 2009).

Penelitian ini fokus pada praktik membaca surat kabar edisi Minggu. Subyek penelitian adalah Kompas Minggu. Kompas menerbitkan surat kabar harian yang disebut Harian Umum Kompas yang terbit setiap hari Senin sampai Sabtu, sedangkan di hari Minggu, Kompas khusus menerbitkan Kompas Minggu. Surat kabar akhir pekan ini disajikan lebih bergaya dan santai, berisikan topik-topik yang tidak sama dengan Kompas harian. Identitas yang diusung oleh Kompas Minggu adalah surat kabar yang menyajikan beragam topik, seperti seni, budaya, masyarakat, gaya hidup, kehidupan urban, kebudayaan pop, kuliner, juga keluarga. Konten yang dihadirkan cukup padat namun dengan pengemasan populer. Karena itu, Kompas Minggu lekat dengan penggambaran "koran piknik", yang direpresentasikan melalui banyak tulisan feature, creative writing, dan konten lainnya.

Dari sekian banyak ragam tulisan yang hadir di Kompas Minggu, peneliti meletakkan fokus utama pada kolom yang bertajuk Catatan Minggu. Kolom ini diasuh sekaligus ditulis oleh Bre Redana, kolumnis yang banyak menulis tentang budaya pop, kesenian, dan gaya hidup, yang kerap dikaitkan dengan pendekatan kajian budaya dan media. Catatan Minggu sendiri hadir di setiap hari Minggu terakhir di setiap bulan. Belakangan ini, Kompas Minggu telah mengubah tajuk kolomnya menjadi Udar Rasa, dengan perubahan pada periode terbit dan penulisnya yang bertambah. Bila dahulu kolom ini hanya terbit satu kali dalam dalam setiap bulan, di hari Minggu terakhir, Udar Rasa terbit lebih rutin pada setiap akhir pekan. Bila kolom ini sebelumnya hanya ditulis oleh Bre Redana, saat ini terdapat kontributor lain, seperti Jean Couteau dan Alissa Wahid. Pengertian kolom sendiri adalah ragam tulisan ringkas sekaligus padat, biasanya berisikan pandangan subyektif penulisnya, lalu terbit secara periodik. Topiktopik yang termuat dalam kolom lahir dari pandangan atau opini tentang suatu perkara yang secara spesifik dibahas oleh penulisnya yang telah dicek oleh editor atau redaksi Kompas. Di sinilah kolom justru ditunggu oleh para pembacanya (Naveed, 2011).

Kolom Catatan Minggu yang diteliti berjumlah tiga buah, terbit pada 14 Juni 2015, 28 Juni 2015, dan 5 November 2017. Ketiganya mengangkat topik serupa yang diuraikan oleh penulisnya, Bre Redana, mengenai narasi-narasi urban, gaya hidup, dan sosial budaya. Judul tiga kolom tersebut adalah Yogya-Magelang, Padang-Bukittinggi, dan Pada Setiap Sudut Kota New York. Bila pada kolom pertama dan keduanya memiliki kaitan, antara lain jeda waktu 
terbit yang tidak terpaut jauh dan menguraikan pandangan kolumnis atas lokasi-lokasi spasial yang pernah dikunjungi, sementara pada kolom ketiga ada rentang waktu terbit terpaut dua tahun, namun tetap membahas masyarakat urban dan kompleksitasnya.

Rumusan masalah dari penelitian ini adalah bagaimana interplay antara teks dengan praksis yang mengusung narasi urban dalam kolom Catatan Minggu. Tujuan dari penelitian ini sendiri adalah menunjukkan diskursus yang diusung oleh ketiga kolom Catatan Minggu tersebut sehingga nampak saling terkait (interplay) antara teks yang tersirat dengan praksis dalam diskursus tersebut. Guna mengetahuinya, penelitian ini menggunakan metode penelitian berupa critical discourse analysis (CDA) yang dikemukakan oleh Teun A. Van Dijk. Teori dan konsep yang digunakan dalam penelitian dijelaskan di bawah ini.

Beberapa penelitian terdahulu yang menjadi acuan, di antaranya adalah penelitian oleh Lestari (2020), Bulan dan Kasman (2018), kemudian Ulinnuha, Udasmoro, dan Wijaya (2013). Naskah penelitian pertama oleh Lestari (2020) menggunakan metode analisis wacana kritis oleh Fairclough untuk wacana komunikasi lingkungan yang termuat di iklan Meikarta. Hasil dari penelitian Lestari menunjukkan agenda setting dalam iklan Meikarta mampu mempersuasi khalayak tentang lingkungan Jakarta yang tidak nyaman untuk ditinggali. Naskah kedua oleh Bulan dan Kasman (2018) menjelaskan bagaimana analisis wacana kritis bisa digunakan sebagai alat analisis dalam teks yang diteliti berupa teks pidato Ahok di Kepulauan Seribu. Teks yang dijadikan acuan adalah video pidato dan transkrip yang dibedah menggunakan AWK Fairclough. Penelitian ini menemukan bahwa Ahok dalam retorikanya menunjukkan ideologi Islami dan feminis untuk mendekatkan diri dengan audiens yang ditemuinya. Lalu penelitian ketiga (Ulinnuha, Udasmoro, dan Wijaya, 2013) ingin melakukan komparasi critical discourse analysis yang dikemukan oleh beberapa ahli, yaitu Fairclough, Van Dijk, Wodak, dan Kristeva dalam kajian sosial dan sastra. Komparasi dalam penelitian hendak melihat bagaimana aspek penting dalam CDA yang meliputi diskursus, praktik sosial, representasi, kuasa, dan intertekstualitas diperlihatkan oleh masing-masing ahli. Peneliti juga menggunakan konsep utama untuk membedah teks yang diteliti, seperti pemaparan berikut ini.

\section{Narasi Urban}

Membangun sebuah kota sama dengan membangun warganya. Maksud dari pernyataan ini terletak pada proses melestarikan reproduksi sosiokultural sebuah kota. Pembangunan kota memerlukan level yang lebih tinggi dalam pertumbuhan ekonomi, sebagaimana pula peningkatan dalam dorongan peradaban (civilization). Karenanya, urbanisasi bisa dilihat sebagai manifestasi dari pemenuhan hak-hak asasi manusia dalam peluang dan nilai ekonomi, dalam hak sosial terutama terkait mobilitas, dan hak-hak kultural warga. Kesalahan fundamental dalam pembangunan kota adalah ketika terlalu berpusat pada arena ekonomi saja, kota dilihat sebatas oleh produktivitas ekonominya saja, tidak secara menyeluruh hingga ke arena reproduksi sosial dan kultural. Meski demikian, urbanisasi sendiri adalah proses berkelanjutan, yang perlu dilakukan terus-menerus. Urbanitas terlahir dalam konteks, baik dalam ruang dan waktu, dalam skema tertentu, dan perlu melawan dikotomi barat-timur atau modern-tradisional (Kusumawijaya, 2006).

Urbanitas berbicara tidak hanya dari wujud kebijakan urban, perubahan sosiologi dan politis, melainkan juga relasi interkultural yang berada dalam kompleksitas sekaligus heterogenitas kehidupan para warga atau penghuni kota. Urbanitas juga tidak lepas dari masalahmasalah. Urbanitas perlu beradaptasi dengan beragam lintasan untuk mengartikulasikan para penghuninya, di mana mereka perlu memaknai interaksi sosial yang terjadi dalam kehidupan urban sekaligus mempertimbangkan kesempatan-kesempatan untuk tidak berjumpa atau menjaga jarak aman. Maka bisa dibilang penghuni atau warga kota (urban dwellers) melakukan 
perjumpaan sekaligus menciptakan jarak satu sama lain. Dari sinilah kota selalu menjadi pusat dari keberagaman, keterbukaan, kedalaman, juga terpisahkan dari prasangka, stigma, sekaligus kritik (Pardo, Prato, dan Rosbrook-Thompson, 2020).

\section{Kapital}

Fokus dari pemikiran Bourdieu adalah pada praktik sosial yang terwujud dalam kehidupan sehari-hari. Baginya tindakan dalam hidup sehari-hari tidak bisa dipahami sebagai perilaku individual saja, namun didorong oleh keputusan-keputusan individual sekaligus supra-individu atau struktur tertentu. Bourdieu mengatur masyarakat dalam dimensi vertikal, yang mana ditunjukkan melalui aktor-aktor dalam kelas sosial yang memiliki kapital ekonomi dan kultural tinggi atau rendah. Pengaturan masyarakat secara vertikal ini bisa secara nyata memperlihatkan bagaimana arena pertarungan atau perjuangan kelas-kelas yang bergantung pada kepemilikan kapital, dalam tujuan memainkan sebuah peran-peran tertentu dalam masyarakat. Kondisi ini melahirkan logika kepemilikan yang menentukan relasi antara kelas sosial dengan praktik. Kapital sendiri bisa diartikan layaknya modal yang dimiliki oleh seseorang, bisa berwujud material maupun aneka atribut yang mengusung signifikansi kultural. Kapital bagi Bourdieu terdiri dari: 1) kapital ekonomi, merupakan sumber yang ada dalam proses produksi dan finansial, kapital ekonomi adalah kapital yang paling mudah dikonversikan dalam wujud kapital lainnya; 2) Lalu kapital kultural yang termuat dalam bentuk-bentuk seperti tingkat edukasi, status sarjana, pengetahuan, kode-kode budaya, cara berbicara, menulis, keterampilan, maupun keterampilan bahasa; 3) Kapital sosial berada dalam posisi sosial aktor-aktor, seperti status, jabatan, gelar, marga, prestis; kemudian 4) kapital simbolik merupakan seluruh bentuk pengakuan (recognition), baik oleh kelompok institusional atau non-institusional (Haryatmoko 2010; Jenkins 1992).

\section{No Sense of Place}

Marshall McLuhan melemparkan suatu istilah yang dinamai global village atau desa/ kampung global yang memiliki maksud bahwa saat ini media mampu menciptakan komunitas tanpa sekat fisik dan lokasi, "no sense of place". Dari sini pula terlahir kajian-kajian mengenai fantasi, alienasi, ketecerabutan (rootlessness), dan familiaritas dalam bentuk-bentuk terbarukan (Durham dan Kellner 2006). Marshall McLuhan menjelaskan bahwa desa global terkoneksikan dengan sistem elektronik yang menjadi bagian dari budaya, McLuhan sudah membayangkan kondisi ini jauh sebelum era desa global betul terjadi di tahun 1960-an. McLuhan menggunakan istilah desa global untuk menggarisbawahi observasi atas electronic nervous system - atau media massa seperti yang kita ketahui sekarang. Saat ini konsep desa global telah menghadirkan citra-citra di depan mata, menunjukkan bahwa kita seakan-akan pernah berada di sana "having been there" tanpa hadir secara fisik melalui media massa. Karena itulah manusia saat ini bisa secara simbolik hadir dalam lokasi-lokasi atau ruang-ruang untuk menandai teritori mereka, menunjukkan kekuatan, bahkan menaklukan teritori tersebut, sebagaimana manusia turut memperlihatkan selera baru mereka atas destinasi baru (Parmeggiani, 2010). Pengertian dari no sense of place mudah ditemukan di era mobilitas global, konsep ini dikemukakan oleh Meyrowitz, yang sebelumnya terinspirasi oleh penemuan desa global oleh Marshall McLuhan dan identitas oleh Erving Goffman. Meyrowitz mengemukakan no sense of place terlahir sebagai konsekuensi dari kelahiran media-media baru dalam komunikasi yang hadir dalam kehidupan manusia. Konsep ini terhubung dengan situasi sosial saat melakukan komunikasi bermedia dan keberadaan lokasi-lokasi fisik di sekitarnya. Kerangka berpikir Meyrowitz dibentuk untuk menegaskan interaksi sosial dan situasi yang melampaui batas-batas lokasi fisik, dalam hal ini terkait pula dengan situasi komunikasi bermedia. Meyrowitz memberikan 
contoh situasi komunikasi dengan media telepon, saat para pelaku komunikasi interpersonal termediasi oleh medium elektronik berupa telepon agar tetap merasa dekat dan terhubung satu sama lain. Begitu pula dengan medium berupa televisi yang memunculkan "para-social interaction" interaksi antara tokoh-tokoh di dalam program televisi dengan audiens yang tidak berada di ruangan yang sama dengan tokoh tersebut. Dengan konsep no sense of place dalam komunikasi media justru memunculkan potensi dalam penggunaan media yang kian plural di suatu waktu (Moores, 2003).

\section{METODE}

Bila subyek penelitian di sini adalah tiga judul dari kolom Catatan Minggu, maka obyek penelitiannya adalah diskursus (discourse). Diperlukan sebuah metode penelitian yang tepat untuk bisa menganalisis diskursus dalam teks yang berisikan narasi urban. Diskursus menjadi jembatan bagi teks dan praksis, karenanya penelitian ini menggunakan CDA sebagai pisau analisisnya. Critical discourse analysis (CDA) adalah tipe riset analitis yang memprioritaskan diskursus sebagai dasar untuk mengkaji adanya kuasa dan penyalahgunaan, dominasi, ketidaksetaraan yang terus direproduksi, dibungkam, yang disiratkan oleh teks dan percakapan dalam konteks sosial politik. CDA menawarkan perspektif berbeda dalam teorisasi, analisis, dan aplikasinya melalui banyak bidang dan lapisan sebagai keseluruhan metodologi. Poin krusial dari CDA adalah bagaimana kesadaran dan kewaspadaan atas apa yang terjadi di sekitar masyarakat menjadikannya sebagai metode yang menolak konsep bebas nilai. CDA menjadi bagian sekaligus dipengaruhi oleh relasi antara pengetahuan dan masyarakat. Dalam penelitian ini CDA yang digunakan adalah yang diuraikan oleh Teun A. Van Dijk, dalam teknis analisisnya Van Dijk melandaskan CDA-nya dalam tiga level, yaitu tekstual, diskursus (interplay antara teks dan praksis), dan pengetahuan sosiokultural (Eriyanto 2008; Schiffrin, Tannen, dan Hamilton 2001).

Pertama adalah level tekstual terdiri dari teks, konteks, dan analisis model peristiwa dari Catatan Minggu. Aspek-aspek yang diteliti antara lain semantik, sintaksis, stilistik, dan retorika. Pemilihan kata, kalimat, gaya menulis, bahkan implikasi dari ketidakhadiran atau absennya suatu teks bisa dicermati dalam level ini. Level tekstual juga menganalisis kerangka teks (outline) yang tersusun dari judul, pendahuluan, konten, penutup, begitu pula dengan kesimpulan dan highlight. Kemudian kedua adalah level diskursus yang memperlihatkan interplay dari mikro dan superstruktur, atau dalam hal ini bisa diartikan sebagai teks dan praksis. Level kedua ini bisa ditunjukkan setelah analisis tekstual selesai. Level diskursus mengindikasikan bagian, sekuens, skema dari kolom Catatan Minggu yang diproduksi oleh Kompas Minggu. Dalam level ini peneliti berupaya mencari tahu diskursus yang diusung oleh sebuah teks. Level diskursus berangkat dari interpretasi makna atas teks yang ditunjukkan melalui penggunaan bahasa, secara khusus adalah dengan menginterpretasi kesadaran mental mengapa bahasa digunakan oleh produsen teks - atau kolumnis dalam penelitian ini. Kondisi ini menandakan bahwa level diskursus perlu dilihat pula dari bagaimana pembentukannya di dalam masyarakat, bagaimana proses produksi dan reproduksinya berjalan sehingga teks bisa memberikan arti pula pada praksis. Ketiga adalah level pengetahuan sosiokultural melihat tema utama yang diangkat oleh kolumnis, Bre Redana, dalam Catatan Minggu yang dia tulis. Tema atau topik utama tersebut adalah hasil dari perputaran isu seputar sosial, budaya, ekonomi, dan kondisi politik. 


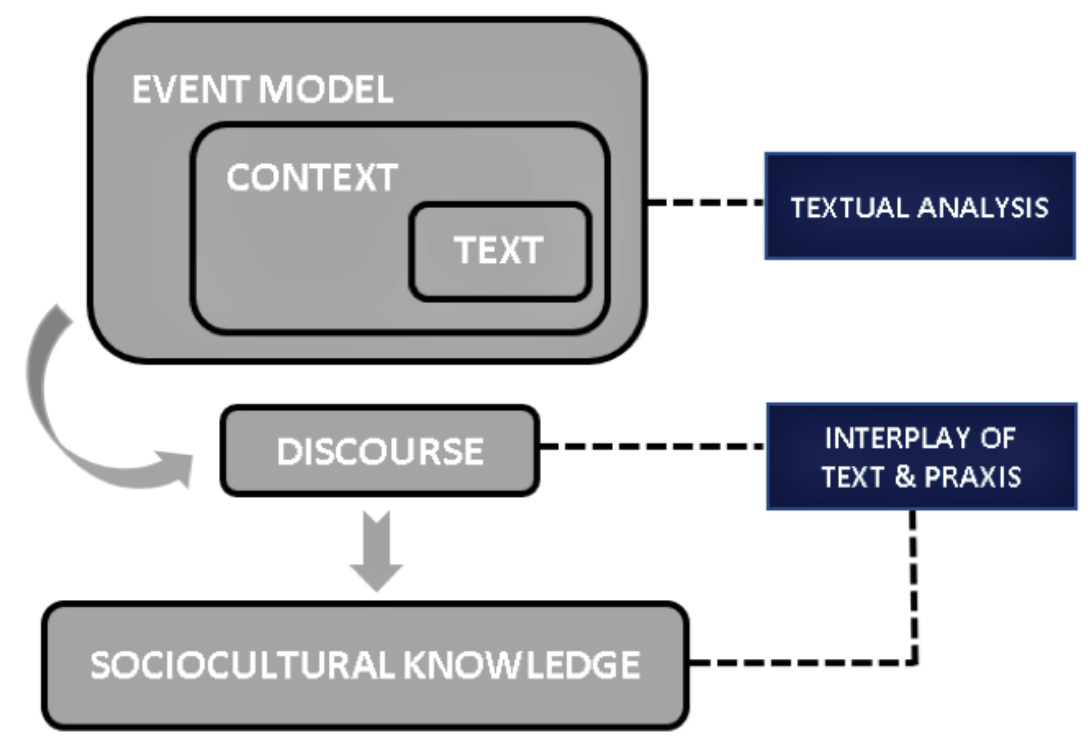

Gambar 1. Teknis Analisis dalam CDA Sumber: (Swastika, 2020)

\section{HASIL DAN PEMBAHASAN}

\section{Teks: Semantik, Sintaksis, Stilistik, dan Retorika}

Diperlukan tiga bagian analisis dalam level tekstual, yaitu analisis teks, konteks, dan model peristiwa. Ketiganya dianalisis secara berurutan untuk memudahkan penarikan hasil, pembahasan, dan kesimpulan. Bagian pertama yang dijelaskan di sini adalah analisis teks, terdiri dari semantik, sintaksis, stilistik, dan retorika yang termuat dalam tiga judul Catatan Minggu. Pengertian dari semantik sendiri adalah makna yang tersirat dalam teks kolom Catatan Minggu, bagaimana detil diberikan pada suatu bagian teks, sedangkan bagian yang lain lebih implisit. Semantik biasa termuat dalam latar, pra-anggapan, dan nominalisasi dalam teks. Lalu sintaksis yang berarti bagaimana sebuah teks kolom disusun oleh bentuk atau susunan kalimatkalimat terpilih, sintaksis ini terletak pada koherensi kata dan kalimat juga pada penggunaan kata ganti. Selanjutnya stilistik, yang mengerucut pada unit lebih spesifik dari sebuah teks, yaitu leksikon atau pilihan kata yang digunakan oleh kolumnis untuk menguraikan pemikirannya. Terakhir adalah retorika yang bisa dilihat dalam penggunaan metafora, ekspresi atau gaya tulisan kolumnis, highlight atau penekanan-penekenan dalam teks (Eriyanto, 2008).

Bila bagian-bagian dari tiga kolom Catatan Minggu pada tabel 1, tabel 2, dan tabel 3 dianalisis pada level tekstual secara menyeluruh, maka hasil yang ditemukan adalah sebagai berikut: semantik menunjukkan bagaimana tiga kolom tersusun oleh latar belakang, anggapan, dan maksud. Maksud yang termuat dalam Catatan Minggu bisa secara eksplisit tersampaikan, namun juga implisit. Bre Redana menyampaikan maksudnya melalui tiga kolom di atas dengan cara menunjukkan apa yang menjadi karakter dari suatu kota, Yogyakarta, Magelang, Padang, Bukittinggi, dan New York. Empat kota dalam negeri dan satu kota berasal dari luar Indonesia, namun semuanya tetap dibandingkan dengan satu kota—yang tampak implisit—yaitu Jakarta. 
Tabel 1. Analisis Teks 14 Juni 2015

\begin{tabular}{|c|c|c|}
\hline $\begin{array}{c}\text { Tanggal \& } \\
\text { Kolom }\end{array}$ & Elemen & Teks Catatan Minggu \\
\hline \multirow{4}{*}{14 Juni 2015} & Semantik & $\begin{array}{l}\text { a. Peristiwa seni membludag di bulan Juni ini. Magnitude-nya mencapai bukan } \\
\text { saja Jakarta, tapi kota-kota di Asia. } \\
\text { b. [...] seperti Singapura, hongkong, serta sejumlah kota di Eropa. Kalangan } \\
\text { seni rupa terdiri dari perupa, kolektor, pengamat, art dealer, galleriest, } \\
\text { artpreneuer, dan kota-kota dunia tumpah ruah di Yogya. } \\
\text { c. Kalau di Yogya seluruh acara dibingkai dalam Jogja Art Weeks (JAW) dengan } \\
\text { lebih dari } 100 \text { lebih program, di Magelang ada Magelang Art Event di mana } \\
\text { belasan galeri di kota ini secara bersamaan menyelenggarakan pameran. } \\
\text { d. Yogya memiliki apa yang sering disebut oleh para ahli urban: vibrant. } \\
\text { Artinya kurang lebih semacam energi, atau daya yang kuat menggerakkan } \\
\text { kehidupan. Dari mana vibrant berasal? Pemikir terkemuka masalah urban, } \\
\text { Richard Florida, menyebut banyak faktor, antara lain terkonsentrasinya } \\
\text { orang-orang berbakat dan produktif. }\end{array}$ \\
\hline & Sintaktis & $\begin{array}{l}\text { a. Judul: Yogya-Magelang } \\
\text { b. Dalam dinamika seni rupa kontemporer Indonesia, Magelang harus disebut, } \\
\text { terutama karena adanya kolektor terkemuka di kota itu, Oei Hong Djien } \\
\text { atau baca OHD. Di Museumnya sekarang, bekerja sama dengan Mizuma } \\
\text { Art Gallery, Tokyo, ia menggelar pameran menampilkan karya-karya perupa } \\
\text { kontemporer [...] } \\
\text { c. Episentrum kegiatan seni rupa ini ART JOG. Memasuki tahun penyelenggaraan } \\
\text { kedelapan, makin jelas bagaimana kegiatan yang dirintis oleh Heri Pemad } \\
\text { tersebut menggerakkan berbagai kegiatan kreatif di Yogya. } \\
\text { d. Efek ikutannya adalah aktivitas ekonomi, hotel, penginapan, restoran, earung } \\
\text { tempat makan lesehan, jasa travel, tukan pijat, dan lain-lain. Di warung Bu } \\
\text { Ageng Butet Kertaredjasa, Anda akan ketemu nama-nama tersohor dari } \\
\text { berbagai kota. Di kedai kopi Epic mendadak ketemu Ketua Badan Ekonomi } \\
\text { Kreatif yang selalu dandy, Triawan Munaf. Melihat dia selalu jadi ingat } \\
\text { Giant Step. }\end{array}$ \\
\hline & Statistik & $\begin{array}{l}\text { a. Kalangan seni rupa terdiri dari perupa, kolektor, pengamat, art dealer, } \\
\text { gallerist, artpreneur }[\ldots] \\
\text { b. Angin kencang menerpa OHD belakangan karena dia dituduh mengoleksi } \\
\text { sejumlah karya palsu. } \\
\text { c. Episentrum kegiatan seni rupa ini ART JOG. } \\
\text { d. Seperti jodoh, kota adalah bagian dari nasib kita. }\end{array}$ \\
\hline & Retorika & $\begin{array}{l}\text { a. Untuk kota, Richard Florida bahkan menggantikan kata ganti where yang } \\
\text { artinya di mana, menjadi who alias siapa. Who's your city? tanya Florida. } \\
\text { b. Nanti kita follow up setelah di Jakarta, katanya. Kembali ke Jakarta, tak } \\
\text { pernah ada kelanjutan. Ketemu lagi pun tidak. Gombal. Di kota yag macet, } \\
\text { sejatinya kebudayaan juga macet. }\end{array}$ \\
\hline
\end{tabular}

Sumber: diolah dari: Swastika (2020)

Tabel 2. Analisis Teks 20 Juni 2015

\begin{tabular}{|c|c|c|}
\hline $\begin{array}{c}\text { Tanggal \& } \\
\text { Kolom }\end{array}$ & Elemen & Teks Catatan Minggu \\
\hline \multirow[t]{2}{*}{28 Juni 2015} & Semantik & $\begin{array}{l}\text { a. Persis sebelum memasuki Bukittinggi, di antara ngarai dan lembah, kami } \\
\text { berhenti di warung di pinggir jalan. Di warung sederhana itu kami melihat } \\
\text { bagaimana lamang dibuat [...]. Kami menikmatinya dengan kawa daun, } \\
\text { minuman panas yang disedu dari daun kopi. Kopi dari Seattle pun tak bakal } \\
\text { mampumenandingi minuman hasil dari kearifan lokal ini. } \\
\text { b. Bahkan lahirnya sivilisasi adalah karena makanan. Dengan ditemukannya } \\
\text { api, manusia mulai mengolah apa yang dimakannya. Itulah yang kemudian } \\
\text { membuat manusia berevolusi secara berbeda dibanding spesies lainnya. } \\
\text { c. Di Sumatera Barat, terasa perjuangan untuk memelihara kekhasan yang } \\
\text { membentuk kebudayaan mereka, termasuk sumber-sumber makanannya: } \\
\text { beras dari Solo, kelapa dari Pariaman, cabai dari Bukittinggi, dan seterusnya. } \\
\text { d. Kalau para sineas Indonesia mampu menyuplai kebutuhan masyarakat di } \\
\text { daerah-daerah dengan film-film yang bercita rasa enak seperti makanan } \\
\text { lokal, kemungkinan dunia film Indonesia akan berkembang sehat. }\end{array}$ \\
\hline & Sintaktis & $\begin{array}{l}\text { a. Judul: Padang-Bukittinggi } \\
\text { b. Di Bukittinggi pula kami bertemu anak muda yang sedang dengan gigih } \\
\text { melakukan pendokumentasian musik dan lagu-lagu lama. Menurut dia, lagu- } \\
\text { lagu Sumatera Barat selalu bersangkutan dengan geografi, makanan, dan } \\
\text { kerajinan. } \\
\text { c. Di Bukittiggi kami mengunjungi Sanggar Saandiko, pimpnan Edi Elmitos. } \\
\text { Edi adalah guru kesenian sekolah dasar. Masa mudanya dulu dia pemain ... }\end{array}$ \\
\hline
\end{tabular}


DOI: $10.24198 / \mathrm{jkj} . v 4 \mathrm{i} 1.27276$

\begin{tabular}{|c|c|c|}
\hline $\begin{array}{c}\text { Tanggal \& } \\
\text { Kolom }\end{array}$ & Elemen & Teks Catatan Minggu \\
\hline \multirow{3}{*}{28 Juni 2015} & Sintaktis & $\begin{array}{l}\text { band rock. Kini, salam sanggarnya, ia olah randai, silat, musik tradisional, } \\
\text { menjadi tampilan bernuansa kontemporer. Proses revitalisasi budaya yang } \\
\text { sangat imajinatif. } \\
\text { d. Bukittinggi, kota di ketinggian kurang lebih } 950 \text { meter di atas permukaan } \\
\text { laut, sekitar dua jam dari Padang, adalah kota yang cantik dan anggun. Andai } \\
\text { lebih bersih, dia bakal anggun luar dalam seperti Bung Hatta yang berasal } \\
\text { dari situ. Senja datang di Bukittinggi, dan kabut pun turun dalam imajinasi } \\
\text { kami. }\end{array}$ \\
\hline & Statistik & $\begin{array}{l}\text { a. Orang setempat berseloroh, kawa daun muncul karena proses kolonialisasi. } \\
\text { Biki kopi dibawa Belanda. Masyarakat setempat meminum daunnya. } \\
\text { b. Bukittinggi }[\ldots] \text { adalah kota yang cantik dan anggun. Andai lebih bersih, dia } \\
\text { bakal anggun luar dalam seperti Bung Hatta yang berasal dari situ. }\end{array}$ \\
\hline & Retorika & $\begin{array}{l}\text { a. Salah satu yang sangat menggairahkan di Sumatera Barat adalah makanannya. } \\
\text { Perjalanan ini, beberapa hari sebelum Ramadhan berlalu, dimaksudkan } \\
\text { untuk survei bagi proyek pertunjukkan "Indonesia Kita" [...] } \\
\text { b. Bukankah ini modal luar biasa kalau dikaitkan dengan keinginan pemerintah } \\
\text { menggalakkkan pariwisata dan ekonomi kreatif? Ia tunjukkan rekaman } \\
\text { video olahannya. }\end{array}$ \\
\hline
\end{tabular}

Sumber: diolah dari: Swastika (2020)

Tabel 3. Analisis Teks 5 November 2017

\begin{tabular}{|c|c|c|}
\hline $\begin{array}{c}\text { Tanggal \& } \\
\text { Kolom }\end{array}$ & Elemen & Teks Catatan Minggu \\
\hline \multirow{4}{*}{$\begin{array}{c}5 \text { November } 2017 \\
\text { Pada Setiap Sudut } \\
\text { Kota New York }\end{array}$} & Semantik & $\begin{array}{l}\text { a. New York adalah panggung bagi mereka yang berkepercayaan: pada dunia } \\
\text { seni spirit manusia berkesempatan mengolah segalanya dari yang riil sampai } \\
\text { imajiner. Bagi penganut kepercayaan tersebut New York adalah tempat } \\
\text { ziarah utama. } \\
\text { b. Pada taman patung terbesar di dunia, Storm King - sekitar satu setengah jam } \\
\text { dari kota New York - warna-warni daun di musim gugur membuat patung- } \\
\text { patung publik para seniman termasyhur sedunia berada dalam puncak } \\
\text { keindahannya untuk dinikmati. } \\
\text { c. Di kota mana pula pada tengah malam seusai pertunjukkan kita bisa } \\
\text { menikmati daging panggang di pinggir jalan? Lalu menumpang angkutan } \\
\text { umum kereta bawah tanah, keluar lagi di jalanan di mana kafe-kafe masih } \\
\text { buka? } \\
\text { d. Tahun ini pula majalah New York (bedakan dengan New Yorker) berusia genap } \\
50 \text { tahun. Memperingati hari jadinya, mereka menampilkan edisi khusus [...] }\end{array}$ \\
\hline & Sintaktis & $\begin{array}{l}\text { a. Judul: Pada Setiap Sudut Kota New York } \\
\text { b. Bagi penganut kepercayaan tersebut New York adalah tempat ziarah utama. } \\
\text { c. Pada musim gugur ketika daun-daun hijau berubah menjadi hijau tosca, } \\
\text { oranye, kuning, merah, coklat, dan seterusnya? Tak ada yang melebihi } \\
\text { vibrasi New York. } \\
\text { d. Ia menyanyikan "New York State of Mind". Ini lebih cerdas. Baginya kota } \\
\text { adalah sebuah "State of Mind", sesuatu yang memengaruhi sistem kognisi } \\
\text { kita. }\end{array}$ \\
\hline & Statistik & $\begin{array}{l}\text { a. Every corner of New York is a stage. } \\
\text { b. Patung-patung berada di lembah rerumputan luas, membuat orang ingin } \\
\text { berdendang, "running through the rain/hand in hand/across the meadow." } \\
\text { Ya, Anda tahu itu lirik lagu Sandra and Andres, "Storybook Children". } \\
\text { c. Distorsi suara gitarnya menjadikan cinta dalam lagu lembut "Speak Softly } \\
\text { Love" menyentak, jujur, tak berdosa, bertenaga. Tak ketinggalan lagu manis } \\
\text { "Noveber Rain". }\end{array}$ \\
\hline & Retorika & $\begin{array}{l}\text { a. Jawab si wanita; saya baca Proust dan menyiapkan disertasi. Ha-ha, saya } \\
\text { bercanda. Suami saa ke luar kota, jadi saya nontn film, Last Night, bintangnya } \\
\text { Keira Knightley. Di manakan ada canda secerdas itu di tempat umum selain } \\
\text { di New York? } \\
\text { b. Ketika agama menjadi tempat teramat sangar dan politik tak lagi bisa } \\
\text { dipercaya, pada apa lagi kita berkaca? Pada kesenian. Di mana? New York! }\end{array}$ \\
\hline
\end{tabular}

Sumber: diolah dari: Swastika (2020) 
Analisis semantik dalam Catatan Minggu juga bisa menjelaskan bahwa tiga kolom ini berangkat dari pengalaman pribadi Bre Redana saat mengunjungi kota-kota tersebut dan melakukan banyak kegiatan. Praktik yang hendak dibicarakan di sini tentu saja adalah pelancongan, kesenian, kebudayaan, dan urbanisasi. Semua praktik ini kemudian dilekatkan dengan kepakaran Bre Redana dalam hal jurnalistik, karenanya Bre menuliskan Catatan Minggu sebagai memoar atas jejak-jejak perjalanannya: lokasi apa saja yang pernah dikunjungi, siapa saja yang pernah ditemui, apa yang ditemukan di kota tersebut dan dibandingkan dengan kondisi di Jakarta, apa yang dia ulas dengan teori-teori kajian budaya dan media. Karakter dari lima kota tersebut disampaikan: Yogyakarta dan Magelang karena vibrasi atau energi keseniannya yang besar, lalu kebudayaan Padang-Bukittinggi yang berevolusi melalui makanan, dan New York adalah pusat pentas dunia. Lalu bagaimana maksud dari teks yang absen. CDA bisa menganalisis sampai ke hal-hal yang menjadi pause atau jeda, begitu pula bagian-bagian yang samar-samar atau hilang. Adalah Jakarta yang menurut pandangan Bre Redana tidak dapat menjadi kota percontohan bagi proses urbanisasi. Di kota ini tidak ada vibrasi, penuh dengan keruwetan dan kemacetan, yang seringkali menjadi alasan bagi para penghuninya untuk tidak berinteraksi dan kurang berkembang (tidak produktif dalam hal ini). Jakarta belum mampu menyodorkan elemen-elemen kepantasan bagi penghuninya untuk hidup (living). Memang warga Jakarta adalah warga yang bekerja, mereka mencari nafkah, mereka bergerak ke sana-sini, namun belum mampu menghuni kota tersebut sepenuhnya sebagai warga kota (inhabitant). Kondisi inilah yang menjadi cerminan bagi Bre Redana, sebab dia menjadi salah satu warganya sendiri, yang menggantungkan hidup justru dari Jakarta. Maka bisa dibilang Catatan Minggu adalah wujud kritik dan ejekan seorang warga yang sebetulnya ingin agar Jakarta segera berbenah.

Selain semantik, analisis teks perlu mempertimbangkan elemen sintaksis. Dalam hal ini peneliti melihat Catatan Minggu sebagai bentuk kolom dengan hakikat-hakikat tertentu. Bahwasanya tulisan dalam kolom tidak bisa bertele-tele dan terlalu panjang, harus ringkas dan padat. Di dalamnya harus memuat kerangka berpikir kolumnis secara jelas, maka kolom pada dasarnya memiliki susunan yang cenderung ajeg atau tidak berubah-ubah. Nampak dalam tiga kolom ini semuanya diawali dari latar belakang, uraian peristiwa, dilanjutkan dengan ulasanulasan konsep yang dikaitkan dengan rujukan literatur atau medium lainnya (musik, buku, dan sebagainya), kemudian ditutup dengan pernyataan kembali. Di akhir bagian Bre Redana sering memberikan penegasan (highlight) atas apa yang dia tuliskan di kolom tersebut. Inilah wujud koherensi dalam Catatan Minggu. Sintaksis juga menunjukkan bentuk-bentuk kalimat yang kerap digunakan oleh Bre Redana dalam Catatan Minggu. Bre sering menyebutkan namanama orang yang dia temui bahkan berteman dekat dengannya, selain itu dia menyebutkan pula nama-nama tempat secara spesifik. Uraian peristiwa yang diceritakannya kerap dituliskan secara naratif, deskriptif, dan kausalistik (sebab-akibat). Selain itu, Bre Redana kerap memasukkan kata-kata kunci yang tidak lumrah digunakan saat bercakap-cakap dalam keseharian, inilah yang disebut sebagai leksikon, antara lain: revitalisasi, vibrasi, episentrum, kontemporer, angin kencang, gombal. Bahkan dia bisa membedakan beberapa tipe pekerjaan terkait bidang kesenian, yang mana orang awam hanya bisa menjelaskan dalam satu kata saja, misalnya "seniman", namun Bre membaginya menjadi perupa, kolektor, pengamat, art dealer, gallerist, juga artpreneur. Kemudian stilistik yang terkait dengan gaya menulis kolumnis. Gaya menulis Bre Redana cukup khas, dia acapkali menggunakan kutipan-kutipan dari sumber rujukan lainnya, seperti penggalan lagu dan isi buku. Tak lupa dia menyebutkan tokoh-tokoh yang dia rujuk, seorang cendekiawan, seniman, maupun tokoh penting lainnya. 
Bagian terakhir adalah retorika. Dalam Catatan Minggu retorika disampaikan untuk menunjukkan highlight dari kolom tersebut. Sebab isi kolom tidak mudah ditebak bila hanya mengandalkan judul saja, karenanya diperlukan retorika agar Bre Redana bisa meyakinkan pembacanya atas pandangan yang dia tulis. Retorika juga menunjukkan sisi subyektif dari sebuah kolom, sebab di situ lahir pemikiran kolumnis yang tidak membutuhkan keterlibatan pembaca untuk mengamininya. Retorika juga menjadi jembatan antara Bre Redana dengan pembacanya untuk mengarahkan mereka pada tahap selanjutnya: teks ini hendak diapakan, bagaimana kemudian respon pembaca, dan efek emosi-kognisi seperti apa yang dipicu oleh retorika kolumnis.

\section{Konteks dalam Kompas, Kompas Minggu, dan Catatan Minggu}

Pada bagian ini, yang perlu dicermati adalah hubungan antara diskursus dengan masyarakat bersifat tidak langsung, di mana perlu dijembatani oleh model konteks seperti struktur sosial, organisasi atau korporat, termasuk di dalamnya proses mental produksi makna. Untuk mengenali mental produksi makna, diperlukan perlengkapan kognitif sehingga kita bisa mengetahui struktur sosial apa yang dapat mengatur diskursus (Haryatmoko, 2016). Penelitian dalam media menjadi bagian dari dunia material (material world), sekaligus peran media dalam memistifikasi atau lebih luas lagi dalam kontribusinya menciptakan realitas sosial. Media, layaknya sistem edukasi, merupakan mekanisme representasi sekaligus sumber-sumber yang menjadi kerangka dalam tindakan-tindakan media mengonstruksi realitas media. Media pada akhirnya menjadi bagian dari realitas keseharian manusia. Karenanya dalam analisis model peristiwa dalam CDA sejalan dengan apa yang diungkapkan oleh Bourdieu dalam field theory, yakni menyibakkan struktur sekaligus mekanisme yang bekerja dalam reproduksi atau transformasi teks. Dalam hal ini peneliti melihat bagaimana media field terbentuk di Kompas, kemudian diturunkan dalam mekanisme produksi-reproduksi Catatan Minggu yang hadir di surat kabar akhir pekan, Kompas Minggu (Couldry, 2003).

Pada tahun 2019 Kompas menempatiurutan pertama sebagai "top newspaper in Indonesia" berdasarkan web ranking, disusul oleh Koran Tempo, The Jakarta Post, Republika, dan Jawa Pos (4 International Media \& Newspaper, 2019). Kompas berdiri sejak 28 Juni 1965, didirikan oleh P.K.Ojong dan Jakob Oetama. Saat ini PT Kompas Media Nusantara berkantor di Jakarta dan menjadi bagian dari kelompok usaha Kompas Gramedia (KG). Mengusung semboyan "Amanat Hati Nurani Rakyat", Kompas telah menjadi bagian penting dalam dinamika pers Indonesia. Kompas sendiri telah tumbuh menjadi salah satu sumber informasi kredibel dan dibaca oleh masyarakat lintas generasi. Saat ini Kompas bisa diakses melalui surat kabar cetak (harian), juga digital platform, yang bernaung di alamat Kompas.id. Kantor redaksi Kompas beralamatkan di Gedung Kompas Gramedia, Jalan Palmerah Selatan 26-28, DKI Jakarta, Indonesia 10270. Detil profil Kompas, di antaranya merupakan surat kabar dengan cakupan pemberitaan nasional, terbit harian dalam format cetak dan online, ukuran surat kabar cetak adalah panjang $600 \mathrm{~mm}$ dan lebar $330 \mathrm{~mm}$, bisa dibeli eceran dan berlangganan, tipe kontennya adalah jurnalistik dan advertorial/iklan, dan memiliki oplah berkisar 500.000 sampai 1.000 .000 eksemplar. Fitur-fitur dalam Kompas antara lain: editorial, politik, berita nasional, berita internasional, berita lokal (metropolitan), bisnis dan keuangan, olahraga, seni budaya, iptek, pelancongan, gaya hidup, hiburan, pendidikan, dan sumplemen seperti perkiraan cuaca, komik, obituari, horoskop, dan klasika (iklan) (4 International Media \& Newspaper, 2019). Harga surat kabar eceran adalah Rp 3.500, bila dibandrol dengan harga langganan per bulan, maka nilainya adalah Rp 78.000, lalu bila harga langganan ditambahkan dengan Kompas Digital Premium dan ongkos kirim maka total satu bulan adalah di kisaran Rp 108.000 (Kompas.id, 2019). Sementara untuk struktur organisasi Kompas dilihat dalam Gambar 2. 
Volume 04 Nomor 01 Tahun 2020

DOI: $10.24198 /$ jkj.v4i1.27276

\begin{tabular}{ll|}
\hline Editorial & \\
Pemimpin Umum & Jakob Oetama \\
Wakil Pemimpin Umum & Lilik Oetama \\
Pemimpin Redaksi/Penanggung Jawab & Budiman Tanuredjo \\
& Mohammad Bakir \\
P. Tri Agung Kristanto & Sutta Dharmasaputra \\
Redaktur Senior & Ninok Laksono \\
Redaktur Pelaksana & Rikard Bagun \\
Wakil Redaktur Pelaksana & Adi Prinantyo \\
& Marcellus Hernowo \\
Sekretaris Redaksi & Antonius Tomy Trinugroho \\
General Manager Litbang & Haryo Damardono \\
(Plt) General Manager SDM-Umum & Subur Tjahjono \\
& Ilham Khoiri \\
Bisnis & F. Harianto Santoso \\
Direktur Bisnis & Budiman Tanuredjo \\
General Manager Iklan & \\
General Manager Marketing & \\
General Manager Event & \\
\hline
\end{tabular}

Gambar 2. Struktur Organisasi Kompas

Sumber: Kompas.id (2019)

\section{Model Peristiwa: Peran Kolumnis dan Produksi Teks}

Dalam model peristiwa peneliti menyuguhkan fakta-fakta yang merepresentasikan peristiwa-peristiwa yang diacu oleh diskursus. Salah satu cirinya adalah pada bagian ini tidak dapat terungkap secara lengkap karena banyak proposisi yang masih tersirat dan harus disimpulkan. Oleh karena itu, dalam model peristiwa banyak memuat asumsi dan perandaian. Model peristiwa bersifat subyektif, yang artinya membutuhkan interpretasi peneliti atas peristiwa. Model peristiwa lebih bersifat semantik dan memiliki skema yang terdiri dari latar belakang, partisipan, dan serangkaian peristiwa-peristiwa.

Tiga kolom Catatan Minggu, dengan judul Yogya-Magelang, Padang-Bukittinggi, dan Pada Setiap Sudut Kota New York adalah teks yang dia produksi sebagai kolumnis Kompas Minggu, di mana Bre Redana juga berada dalam struktur organisasi Kompas sebagai seorang jurnalis. Bre Redana pernah mengikuti kuliah kajian media di Darlington College of Technology di Inggris pada tahun 1990-1991, fokus tulisannya berada di bidang-bidang seputar kehidupan masyarakat Jakarta, gosip artis, tren, hingga toko-toko mewah di kota besar. Tulisannya dikemas dalam laporan jurnalistik yang bisa dibaca oleh berbagai kalangan, Bre Redana sendiri melihat pekerjaan jurnalistiknya bukan sekedar sumber pendapatan, melainkan juga panggilan. Pendidikan sekolah dasarnya di SD Kanisius (1970) dan SMP Negeri 2 (1973) ditamatkan di kota kelahirannya, Salatiga, Jawa Tengah. Selanjutnya Bre melanjutkan ke STM Kristen Klaten, setelah tamat dia berkuliah di jurusan Bahasa Inggris di Universitas Kristen Satya Wacana, Salatiga. Semasa kuliah Bre mulai berkenalan dengan dunia jurnalistik, terutama saat dia aktif bergerak di pers mahasiswa Gita Mahasiswa. Meski sebelumnya, Bre kerap mengirimkan karangan fiksi cinta saat duduk di bangku STM, saat berkuliah dia mulai mengirimkan tulisan 
ke Harian Kompas, meskipun tidak ada satu pun tulisannya diterima. Justru, di Sinar Harapan dan Merdeka, tulisannya banyak dimuat. Sejak kecil Bre Redana memang sudah dekat dengan dunia tulis menulis, awalnya karena Bre Redana gemar membaca dan sudah berkenalan dengan majalah ternama, seperti Horison, Prisma, MIDI, dan sebagainya. Ibunyalah, Yutinem, yang mengenalkan Bre pada dunia (Badan Pengembangan dan Pembinaan Bahasa 2019).

Tahun 1981 setelah lulus dari Satya Wacana, Bre Redana diterima sebagai wartawan di Harian Kompas, yang sebelumnya tidak pernah menerima satu pun tulisannya, sebagai jurnalis muda. Dia ditempatkan di rubrik IPTEK, selanjutnya pindah ke rubrik kota, olahraga, luar negeri, sampai akhirnya membidani rubrik budaya. Bagi Bre Redana sangat menyenangkan menangani kolom budaya yang sesuai dengan bakat dan minatnya. Sejak anak-anak Bre memang dekat dengan kesenian tradisi, seperti ketoprak, tayub, dan tarling. Ditambah lagi kegemarannya akan pencak silat yang sudah didalami lebih dari lima belas tahun. Hingga saat ini, selain menjadi jurnalis di Kompas dan membidani kolom Catatan Minggu, Bre Redana juga menerbitkan beberapa buku. Dua buku yang saling berkaitan telah diterbitkannya dengan nama pena Gitanyali, adalah Blues Merbabu dan 65, merupakan novel ciptaannya yang memadukan persoalan pop culture dengan isu politik tahun 1965. Dua novel layaknya memoar karena mencakup kesukaannya dan latar belakang kehidupan keluarganya yang amat dekat dengan isu PKI, sebab ayahnya yang seorang kader PKI di Salatiga pernah dijemput paksa dan ditahan di suatu tempat yang tidak diketahui di saat umur Bre delapan tahun, dan hingga saat ini tidak pernah berjumpa lagi. Bre Redana — alias Gitanyali, alias Don Sabdono, nama aslinya — enggan menyebutkan tanggal lahirnya, berkeinginan setelah pensiun dari Kompas, tidak ingin mencari pekerjaan lain di media massa. Dia ingin menikmati masa pensiunnya dengan menulis (Badan Pengembangan dan Pembinaan Bahasa 2019).

\section{Level Diskursus}

Fairclough (1995) melihat diskursus sebagai bahasa yang merepresentasikan praktikpraktik dari perspektif yang khusus. Dialog adalah persyaratan utama bagi diskursus, seluruh percakapan perlu diterapkan dalam ruang-ruang sosial, di mana semua kata dan makna bergantung pada tempat dan tujuan dari pembentukannya. Oleh karena itu, diskursus, suatu arena khusus dalam bahasa, dapat dikenali melalui institusi-institusi yang relevan dan posisi di mana diskursus diproduksi. Maknanya kemudian muncul melalui perekaan dan interpretasi, pelembagaan, pola-pola tindakan, dalam tatanan produksi, transmisi, dan pedagogi (Macdonell 2005). Level diskursus mensyaratkan analisis yang menyeluruh atas representasi kognisi dan strategi produsen dalam memproduksi teks berupa kolom (Eriyanto 2008). Level diskursus dalam penelitian ini menyibakkan akumulasi kapital Bre Redana selaku produsen teks Catatan Minggu dalam rutinitas media.

Titik berat pemikiran Bourdieu berada pada praktik-praktik sosial yang terwujud dalam kehidupan sehari-hari masyarakat. Baginya tindakan keseharian orang-orang tidak bisa dipahami sebagai tingkah laku individual, yang terdorong dari pengambilan keputusan secara individual, namun ditentukan pula oleh "supra-individual" atau struktur tertentu (Haryatmoko 2010; Jenkins 1992). Bourdieu menata masyarakat dalam dimensi vertikal, dengan demikian terlihat manakah pelaku-pelaku dalam kelas sosial yang memiliki kapital ekonomi dan budaya tinggi dengan mereka yang lemah. Baginya penataan seperti ini akan terlihat jelas arena perjuangan, apa yang dipertaruhkan, dan jenis kapital yang diperlukan untuk berperan dalam permainan, yang mengarahkan logika kepemilikan sehingga dapat menentukan hubungan antara kelas sosial dan praktiknya (Haryatmoko, 2010). Definisi kapital bagi Bourdieu sangat luas dan mencakup halhal material dan beragam atribut yang mengandung signifikansi kultural dalam diri Bre Redana (Bourdieu 1986, 2013; Bourdieu and Wacquant 1992). Kapital ekonomi merupakan sumber 
daya yang bisa menjadi sarana produksi dan finansial Bre Redana, kapital ini paling mudah dikonversikan ke kapital lainnya, bisa berupa penghasilan Bre sebagai jurnalis, honorarium yang diterimanya sebagai penulis atau pembicara, investasi bisnis, kepemilikan barang-barang, konsinyasi atau kerjasama yang menghasilkan keuntungan ekonomi bagi Bre Redana. Kapital budaya bisa berupa jenjang pendidikan yang ditempuh Bre Redana, ijazah yang dia miliki, pengetahuan yang dia punyai dan bisa dibagikan dalam media maupun forum-forum tertentu, kode budaya yang melekat dalam diri Bre Redana. Kapital budaya termasuk di dalamnya adalah kemampuan menulis Bre Redana yang menjadi profesi baginya, kemampuan berbahasa, serta kepakaran yang dimiliki Bre Redana yang berperan dalam penentuan kedudukan sosialnya. Kapital budaya bisa hadir dalam tiga bentuk, yaitu (a) embodied state, yang bisa ditemukan dalam watak tubuh dan pemikiran Bre Redana; (b) objectified state, terkandung dalam produkproduk budaya, kolom Catatan Minggu yang dia hasilkan rutin di Kompas Minggu, buku-buku yang dia tulis, maupun artikel-artikel lain yang dia tulis di surat kabar. Lalu (c) institutionalized state, yang ditemukan dalam kualifikasi edukasi Bre Redana. Diketahui bahwa Bre Redana menempuh jenjang pendidikan pascasarjana di Inggris, mengambil program studi Media Studies, selain sebagai lulusan sarjana Bahasa Inggris.

Sementara kapital sosial bisa termuat dalam jabatan, gelar, status, nama keluarga, atau prestis tertentu yang dimiliki Bre Redana. Bre jelas memiliki status baik sebagai jurnalis senior di Kompas, meski usianya kian senja, Bre masih aktif menghasilkan karya dan mengisi forumforum seni budaya sebagai pembicara. Diketahui pula Bre Redana dekat dengan kalangan seniman, sebab pasangannya adalah kurator sekaligus pemilik galeri seni. Kapital simbolik adalah semua bentuk pengakuan oleh kelompok, baik secara institusional atau non-institusional, yang diberikan kepada Bre Redana. Kapital simbolik yang dihadirkan oleh penghargaanpenghargaan resmi bisa jadi diakui, dijamin, dan secara yuridis terlembagakan. Penghargaan resmi saat seseorang dianugerahi sebuah titel atau kualifikasi yang diakui secara sosial adalah salah satu ekspresi yang mana monopoli di dalamnya melampaui kekerasan simbolik yang dimiliki oleh negara atau representatif. Kekuasaan simbolik, dalam hal ini, adalah kekuasaan untuk penentuan posisi. Kekuasaan simbolik bisa menjadi kekuatan konstitusi, baik di dalam aspek filosofis maupun politis (Bourdieu, 2013; Haryatmoko, 2010). Kapital simbolik adalah yang bisa mendominasi lanskap sosial seseorang, kapital ini nampak natural melekat di diri seseorang, dan bersifat arbitrer. Kapital simbolik bisa ditemukan dengan memperhatikan habitus seseorang secara spesifik, dalam ini bisa memperhitungkan habitus Bre Redana sebagai seorang jurnalis dan kolumnis yang bekerja di sebuah media nasional di Jakarta.

Seluruh kapital yang terkandung dalam arena jurnalistik, merupakan akumulasi dari kapital ekonomi, sosial, budaya, simbolik mengarahkan pada apa yang disebut sebagai media capital (capital médiatique), merupakan pengaruh yang sangat potensial dan ampuh untuk memberikan pengaruh atas apa yang dihasilkan di arena tersebut. Bre Redana dalam situasi ini telah mengakumulasikan kapital yang dia miliki, bahkan selama bertahun-tahun mengingat pengalamannya bekerja menjadi jurnalis telah terjadi puluhan tahun — bisa dilihat pada analisis model peristiwa. Kapital-kapital ini pula bisa saling dipertukarkan satu sama lain dalam arenanya, arena jurnalistik, masing-masing kapital pun bisa memiliki nilai yang lebih tinggi atau rendah satu sama lain, bila diakumulasikan semuanya bisa menunjukkan seberapa kuat kuasa media di dalamnya (Couldry, 2003).

\section{Level Sosiokultural}

Analisis dalam tingkatan ini mengasumsikan bahwa konteks sosial dan kultural mempengaruhi bagaimana diskursus muncul dalam praktik bermedia juga menentukan bagaimana teks diproduksi dan direproduksi. Analisis di level sosiokultural menjelaskan 
bagaimana teks media, Catatan Minggu, terhubung dengan situasi di luar teks tersebut, seperti situasi ekonomi politik, sosial, budaya. Di level ini pemahaman intertekstualitas dibutuhkan peneliti untuk menghubungkan teks-teks kolom Catatan Minggu dengan situasi yang lebih makro. Peristiwa atau situasi-situasi ini memperlihatkan bahwa teks tidak semata-mata ada, melainkan turut membentuk praksis; begitu sebaliknya praksis sosial yang terjadi turut mempengaruhi cara jurnalis memproduksi-mereproduksi teks. Hal yang penting dalam analisis level sosiokultural adalah bahwa interplay antara teks dan praksis berada pada hubungan dialektis yang berjalan aktif dan tidak terlepas dari praktik kekuasaan yang ada (Robin, Shella, dan Adiniwinata, 2020).

Kondisi global village merujuk pada ujaran Marshall McLuhan, yang mana media massa menciptakan komunitas dengan "no sense of place" (Durham dan Kellner, 2006). Pandangan Marshall McLuhan mengenai konsep desa global yang terkoneksi oleh sistem elektronik yang menjadi bagian dari kebudayaan populer, sudah dibayangkan olehnya hadir jauh sebelum kondisi ini betul terjadi. Bagi McLuhan terdapat tiga inovasi teknologi yang paling utama yaitu penemuan alfabet fonetik yang mengguncangkan kehidupan tribal, di mana sebelumnya manusia berpegangan pada keseimbangan sensor-sensor di tubuh mereka lalu beralih pada dominasi mata (pandangan). Inovasi kedua adalah huruf cetak atau huruf-huruf balok (movable type) pada abad ke-16 yang mengakselerasi proses sebelumnya yakni penemuan alfabet fonetik sehingga menjadi lebih cepat, disusul penemuan ketiga adalah telegraf di tahun 1844 yang mewartakan revolusi industri yang mengubah kehidupan tribal. Bagi McLuhan seluruh aspek kebudayaan mekanis di dunia barat terinspirasi atau terdorong oleh teknologi percetakan, namun era modern adalah era media elektronik. Media elektronik seperti telegraf, radio, film, telefon, komputer, televisi, dan Internet semuanya tidak hanya memperpanjang satu indera atau fungsi tubuh manusia seperti media mekanis tua sebelumnya, seperti roda sebagai perpanjangan dari kaki, pakaian sebagai perpanjangan dari kulit, atau alfabet fonetik sebagai perpanjangan dari mata. Seluruh media elektronik menjadi perpanjangan dari seluruh central nervous system manusia, karenanya mentransformasikan semua aspek dalam kehadiran fisik dan sosial manusia (Swastika, 2016).

Pada akhirnya, tidak ada lagi dunia kultural yang terikat secara spasial dari tempat dia berangkat dan kembali, tidak ada lagi pemahaman dunia kultural yang tradisional dan kaku. Sebab saat ini migrasi informasi, mitos, bahasa, musik, citra, ragam kuliner, dekorasi, kostum, pernak-pernik, dan terlebih lagi orang-orang, bisa membawa lokasi yang paling terisolasi ke dalam bingkai interaksi sosio-kultural yang global dan kosmopolitan. Secara bersamaan para penghuni tetap bisa berdiam di rumah sambil melancong ke tempat lainnya. Seiring dengan penambahan kuantitas mobilitas fisik, kesadaran terhadap pergerakan citra-citra melalui media massa juga meninggi, keduanya semakin menegaskan pembauran di banyak wilayah, serta mempertajam perhatian terhadap wujud-wujud budaya yang tidak dimiliki atau diketahui oleh orang-orang sebelumnya (Morley, 2000).

Dari ketiga kolom Catatan Minggu yang diteliti di sini, Yogya-Magelang, PadangBukittinggi, dan Pada Setiap Sudut Kota New York, ketiganya menjelaskan konsep ulang-alik heim dan heimat. Dalam Bahasa Jerman keduanya memiliki maksud: heim adalah kawasan tempat tinggal dalam lingkup domestik, atau rumah yang kita tinggali, menjadi ruang intim para penghuninya; sedangkan heimat adalah kawasan tempat tinggal dengan cakupan lebih luas, seperti tempat kelahiran atau tanah air. Bila rumah dalam cakupan domestik melibatkan intimitas di antara orang-orang yang menghuni, konsep tempat lahir atau tanah air justru lebih banyak melibatkan orang-orang asing yang terikat oleh konsep komunitas terbayangkan (imagined community). Maka selanjutnya heimat merupakan hasil konstruksi sosial yang dipengaruhi 
oleh mediasi di antara orang-orang, komunitas, obyek, juga atribut dalam kawasan tersebut. Dan hari ini, di tengah situasi komunikasi media yang kian masif dan canggih, saat mobilitas dan globalisasi menghapuskan sekat-sekat fisik, media menjadi wujud dari heimat yang mutakhir. Sebab pada hakikatnya, media menghasilkan realitas di mana audiens seakan menjadi komunitas-komunitas yang terikat oleh satu kesamaan, suatu obyek yang sama-sama sedang dikonsumsi, atribut yang melekat pada diri audiens juga turut membentuk kepemilikan atas heimat mereka. Maka bisa dibayangkan bagaimana pembaca Catatan Minggu membayangkan komunitas mereka, saat mereka mengonsumsi bacaan akhir pekan di hari Minggu, menyantap suguhan teks berupa Catatan Minggu.

Penelitian ini juga mengerucut pada tiga kolom yang memiliki topik serupa dengan pembahasan urbanisasi, modernitas, gaya hidup, diaspora, pelancongan, rumah, semuanya yang berelasi dengan narasi urban. Dalam konsep diaspora dan media sendiri, ruang antara bangsa, kawasan dan identitas, lalu cara manusia memandang (gaze) yang melewati dan melintasi batasan ruang disebut sebagai narrowcast media. Dalam hal ini, media seperti televisi dengan satelit, radio, Internet, film, pers kerap dimanfaatkan audiens sebagai instrumen mereka mempertahankan apa yang mereka bayangkan sebagai rumah, begitu pula bayangan audiens atas identitas mereka sebagai bagian dari komunitas diasporik (Budarick, 2003).

Tiga kolom Catatan Minggu yang diteliti bisa memunculkan pula "homing desire", hasrat untuk kembali ke rumah, melalui praktik-praktik kultural dan teks yang memunculkan rasa memiliki atas suatu tempat (a place of belonging). Pengakuan atas rumah atau merasa di rumah saat ini tidak melulu dibatasi oleh konsep primordial, melainkan telah bertransformasi pada praktik-praktik penciptaan simbol dan ruang-ruang. Oleh karena itu, konsep diaspora menjadi tepat bila dilekatkan pada homing desire, sebab situasi diaporik mensyaratkan re-kreasi sebuah ruang alternatif di mana para penghuninya bisa merasakan sense of belonging dan bisa mengaburkan pemetaan sebelumnya yang telah usang. Inilah wujud dari re-territorialisation. Selain membatasi perbatasan negara-bangsa, termasuk siapa yang berada di dalam dan di luar mereka, media juga terlibat dalam artikulasi apa artinya menjadi warga negara secara kultural (cultural citizen). Media dengan demikian merupakan bagian dari rutinitas dan praktik seharihari yang melekat yang mengarah pada pemahaman akan suatu tempat sebagai rumah, yang, secara fenomenologis, audiens telah membenamkan tubuh mereka ke dalam rutinitas ruangwaktu (Budarick, 2003).

\section{SIMPULAN}

Dengan melihat dan mengukur besar kecil kapital yang dimiliki oleh Bre Redana, kemudian mengakumulasikan seluruh kapital tersebut supaya menjadi modal dalam arena tertentu, kapital yang dimiliki oleh Bre Redana dapat dilihat dari watak, sejarah biografi, habitus yang terbentuk oleh dirinya, hingga dalam struktur sosial seperti apa kapital tersebut diartikulasikan. Dalam hal ini Bre Redana memiliki semua kapital, baik itu kapital ekonomi, kultural, sosial, dan simbolik. Volume masing-masing kapital tidaklah sama, namun akumulasi dari kapital Bre Redana tersebut menghasilkan kapital media, yang menjadi kunci berlangsungnya kolom Catatan Minggu dalam dunia jurnalistik. Kapital media diperlukan sebuah teks media supaya diyakini oleh para pembaca, pemirsa, pendengarnya agar sahih dalam diskursus masyarakat. Sebab dari sinilah teks media menghasilkan citra-citra mereka dan mentransimisikan pesan-pesan tertentu pada audiens. Dari Catatan Minggu pula, kita bisa memahami situasi sosial, politik, kultural yang lebih makro yang turut memberikan pengaruh pada produksi-reproduksi teks. Kolom Catatan Minggu yang dikaji melalui CDA menununjukkan adanya saling pengaruh (interplay) antara teks dengan praksis berupa praktik membaca surat kabar akhir pekan. Narasi urban 
yang diangkat oleh Catatan Minggu pun berkelindan dengan praktik keseharian masyarakat, terutama di kawasan perkotaan, yang mengalami dinamika dan urbanisasi yang berkelanjutan. Urbanisasi yang tidak pernah selesai demi mengartikulasikan kehidupan warga (city dwellers) yang tinggal, berumah, yang melakukan aktivitas di dalam kota mereka, yang bekerja, hingga pada pratik-praktik di waktu luang mereka. Membaca surat kabar Kompas Minggu di akhir pekan menjadi perwujudan dari keseharian masyarakat kota (urban) saat mereka berhenti sejenak dari rutinitas pekerjaan atau harian, mereka lalu tinggal di tempat tinggal masingmasing lalu membaca surat kabar di waktu luang mereka.

Media massa sebagai medium publik akhirnya memasuki pula ranah privat masyarakat kota. Kompas Minggu menempati sentral-sentral mental masyarakat kota dan melebur dalam ruang-ruang spasial mereka. Citra yang diciptakan oleh media menerpa para pembaca, yang seringkali tidak disadari, aneka citra tersebut kemudian mengikat para pembaca berdasarkan ikatan-ikatan yang terbayangkan (imagined), sehingga muncul komunitas terbayangkan berupa konsumen-pembaca Kompas Minggu. Dari sekian banyak rubrik, macam tulisan, dan suplemen yang termuat di Kompas Minggu, peneliti secara khusus memfokuskan pada diskursus yang hadir dari Catatan Minggu. Sebuah kolom yang muncul dengan periodesasi tertentu, juga dengan tema khusus, dan membawa nama besar penulisnya. Meski Bre Redana adalah jurnalis senior dan kolumnis yang membidani langsung kolom Catatan Minggu, namun produksi teks di sebuah korporat media tetap memerlukan skema tertentu. Dalam hal ini Kompas Minggu yang berada di bawah redaksi dan manajemen Harian Umum Kompas, berada pula di bawah payung korporasi Kompas Gramedia Group, melakukan rutinitas produksireproduksi teks media nasional. Kolumnis seringkali menuliskan pikiran maupun pandangan mereka atas sesuatu, dengan gaya (style) mereka, perlu diawali dengan proses meliput dan merekam data-data. Meski bersifat subyektif, tulisan kolumnis seperti Bre Redana harus dapat dipertanggungjawabkan dengan menuliskan hal-hal faktual dan tidak melakukan fabrikasi. Dalam hal ini Kompas Minggu telah menciptakan realitas media yang ditransmisikan pada para pembaca. Narasi urban yang menjadi diskursus utama dalam penelitian ini muncul dalam konteks di mana Catatan Minggu diproduksi dalam melalui skema produksi juga rutinitas media tertentu.

Dalam konteks globalisasi era modern, setelah penemuan konsep desa global, terdapat situasi no sense of place. Para pembaca Catatan Minggu tanpa beranjak dari lokasi mereka masing-masing dapat mengunjungi lanskap-lanskap kota lain, tanpa beranjak dengan membaca kolom tersebut mereka bisa mengetahui bagaimana narasi urban terbentuk di lima kota, Yogyakarta, Magelang, Padang, Bukittinggi, dan New York. No sense of place juga mengarahkan pembaca pada konsep heim dan heimat di era modern, saat rumah yang awalnya dipahami sebagai urusan domestik, kini setelah media massa hadir dan masuk hingga ke ranahranah privat, pembaca membayangkan suatu komunitas yang diikat oleh kesamaan-kesamaan, inilah heimat. Narasi urban yang diceritakan dan disampaikan oleh Bre Redana dalam Catatan Minggu bertemu dengan narasi urban yang diciptakan oleh para pembaca, keduanya dipersatukan dalam teks yang muncul pada akhir pekan, saat kebanyakan masyarakat kota beristirahat dan menikmati waktu luang mereka.

\section{DAFTAR PUSTAKA}

4 International Media \& Newspaper. 2019. Top Newspaper in Indonesia.

Badan Pengembangan dan Pembinaan Bahasa. 2019. Bre Redana.

Bourdieu, P. 1986. The Forms of Capital. Pp. 241-58 in Handbook of Theory and Research for

Sociology of Education, edited by J. Richardson. New York: Greenwood. 
Volume 04 Nomor 01 Tahun 2020

DOI: $10.24198 / j k j . v 4 i 1.27276$

Bourdieu, P. 2013. Social Space and Symbolic Power. Sociological Theory 7(1):14-25.

Bourdieu, P. and L. J. Wacquant. 1992. An Invitation to Reflexive Sociology. UK: Polity Press. Budarick, J. 2003. Media, Home, and Diaspora. London.

Bulan, Arif and Kasman Kasman. 2018. Critical Discourse Analysis of Ahok's Speech in Kepulauan Seribu. Transformatika: Jurnal Bahasa, Sastra, Dan Pengajarannya 2(1):50. cbsnews.com. 2009. A History of Sunday.

Couldry, N. 2003. Media, Symbolic Power, and The Limits of Bourdieu's Field Theory. London. Durham, Meenakshi Gigi and Douglas M. Kellner. 2006. Media and Cultural Studies Keyworks. Revised. UK: Blackwell Publishing Ltd.

Eriyanto. 2008. Analisis Wacana: Pengantar Analisis Teks Media. Yogyakarta: LKis.

Fairclough, N. 1995. Media Discourse. London: Edward Arnold.

Haryatmoko. 2010. Habitus Dan Kapital Dalam Strategi Kekuasaan: Teori Strukturasi Pierre Bourdieu Dengan Orientasi Budaya. Yogyakarta.

Jenkins, R. 1992. Key Sociologist: Pierre Bourdieu. London: Routledge.

Kompas.id. 2019. Kompas Digital Premium, Koran, Dan Ongkos Kirim.

Kusumawijaya, Marco. 2006. Kota Rumah Kita. Jakarta: Borneo Publications.

Lestari, Christina Arsi. 2020. “Wacana Komunikasi Lingkungan Dalam Iklan Properti Meikarta. 17(1):91-106.

Macdonell, D. 2005. Teori-Teori Diskursus: Kematian Strukturalisme Dan Kelahiran Posstrukturalisme Dari Althusser Hingga Foucault. Jakarta: Penerbit Teraju.

Moores, S. 2003. Media and Senses of Place: On Situational and Phenomenological Geographies. London.

Morley, David. 2000. Home Territories: Media, Mobility, and Identity. London: Routledge.

Naveed, F. 2011. Column: Definition, Types of Column, and Writing Column. Masscommunicationtalk.Com.

Pardo, Italo, Giuliana B. Prato, and James Rosbrook-Thompso. 2020. Ethnographies in Urbanity in Flux: Theoretical Reflections. Urbanities 10(3):1-12.

Parmeggiani, Paulo. 2010. Integrating Multiple Research Methods: A Visual Sociology Approach to Venice. Tourism and Visual Culture 2 (Methods and Cases):94-110.

Robin, P., F. Shella, and A. Adiniwinata. 2020. Analisis Waca Kritis \#JKWVLOG. Calathu: Jurnal Ilmu Komunikasi 2(1):43-58.

Schiffrin, Deborah, Deborah Tannen, and Heidi E. Hamilton. 2001. Handbook of Discourse Analysis. Oxford: Blackwell.

Swastika, Gabriela LD. 2016. Strategi Kapital Dan Gender Di Ruang Siber: Studi Kasus Akun Bertema Food\&Travel,@legalnomadsDan@girleatworld." Graduate School Program, Universitas Gadjah Mada Yogyakarta.

Ulinnuha, Roma, Wening Udasmoro, and Yahya Wijaya. 2013. Critical Discourse Analysis: Theory and Method in Social and Literary Framework. Indonesian Journal of Applied Linguistics 2(2):262-74. 